\title{
Oxidative Stress on Buccal Mucosa Wound in Rats and Rule of Topical Application of Ethanolic Extracts of Mauli Banana (Musa acuminata) Stem
}

Wenda Fitriati Noora ${ }^{{ }^{\star}}$, Novie Apriantia ${ }^{1}$, Saldy Rizky Saputra ${ }^{1}$, Balqis Afifah ${ }^{1}$, Maharani Laillyza Apriasari $^{1}$, Eko Suhartono ${ }^{2}$

\author{
${ }^{1}$ Dentisty Program, Faculty of Medicine, University of Lambung Mangkurat, Banjarmasin, Indonesia \\ ${ }^{2}$ Medical Chemistry and Biochemistry Department, Faculty of Medicine, University of Lambung Mangkurat, Banjarmasin, Indonesia
}

\section{ABSTRACT}

The present study was undertaken to evaluate the effect of a topical application of ethanolic extracts of Mauli banana stem on oxidative status in buccal mucosa wounds of rats. The sets involved three groups, P0 was the negative control; P1 was treated with alocair topically; and P2 was treated with ethanolic extracts of Mauli banana stem topically, respectively, $24 \mathrm{~h}$ after wound creation for 3 days. The oxidative stress status was evaluated by monitoring the SOD, CAT activity, MDA and CC levels. Ethanolic extracts of Mauli banana stem showed significantly increased in SOD activity, decreased in MDA levels, and no significant change both in CAT activity and CC levels compared to negative control. These results showed that The ethanolic extracts of Mauli banana stem might affect the oxidative stress status during wound healing process.

Keywords: antioxidant, free radicals, mauli banana, oxidative stress, wound healing

\section{INTRODUCTION}

South Kalimantan Indonesia is a tropical country that has a variety of fruits [1]. In this province, medicines based on herbal origin have been the basis of treatment and cure for various diseases. A large number of plants are used by folklore traditions in Indonesia. In this day, the use of traditional plants for wound healing has received much attention [2]. It is because these herbal drugs have real effectiveness wit low side effects and cost [3].

It is well known that conditions such as wound increase oxidative stress. Hence, if there is a compound has antioxidant content and activity, it can be an excellent therapeutic agent for enhancing the wound healing process. Antioxidants are capable of promoting rapid reepithelialization of acute wounds and burns and have antimicrobial properties [4].

Mauli banana (Musa acuminata) is a famous and delicious banana that grows plenty throughout Kalimantan Selatan [5]. It is well known that all the parts this plant are beneficial to in the medical aspects and ornamental uses $[6,7]$. The beneficial medicinal effects of these plants materials typically result from the com-

\footnotetext{
${ }^{*}$ Corresponding author:

Eko Suhartono

Medical Chemistry and Biochemistry, Faculty of Medicine, University of Lambung Mangkurat, Banjarmasin, Indonesia Phone: +6-281-251-126368, E-mail: ekoantioxidant@gmail.com
}

binations of antioxidant content in this parts of this plants [8].

Our previous study showed Mauli banana stem contained bioactive compounds such as ascorbic acid, $\beta$-carotene, lycopene, tannin, saponin, and flavonoid. Mauli banana stem have antioxidant activities and/or free radical scavenging activity [5]. Since ROS was involved in wound healing, the presence of those antioxidants might be important in the successful treatment of wounds. Thus, in this present study we investigated the effect of Mauli bananas stem ethanolic extracts on oxidative stress status during buccal mucosa woundhealing.

\section{MATERIALS AND METHODS \\ Research Design}

This research was a true experimental study with post test-only with control design to test the effect of Mauli banana stem ethanol extract on buccal mucosal wound healing in rats (Rattus novergicus).

\section{Plant Materials}

The stem of Mauli banana was collected from a farmland at the school of agriculture Banjarbaru South Kalimantan Indonesia and authenticated by Department of Biological Science, Faculty of Science, Lambung Mangkurat University.

Mauli banana stem ethanolic extract was prepared 


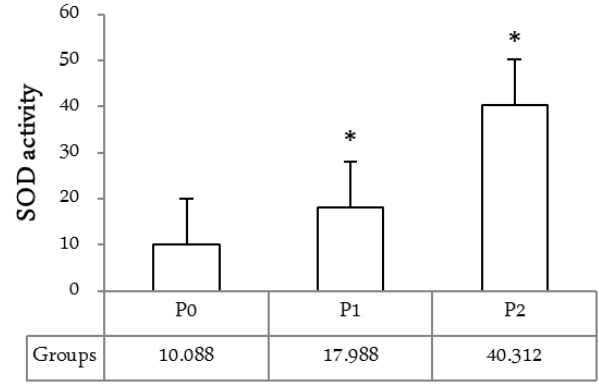

A

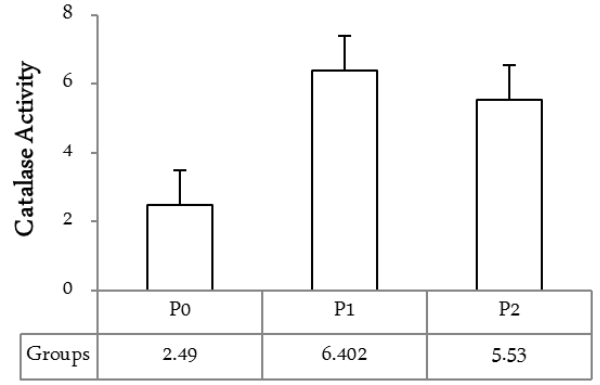

B

Figure 1. A. SOD activity between groups. Values are expressed as mean \pm SEM from 9 rats per group. ${ }^{*} \mathrm{P}<0,05$ vs. P0 group by us ing one-way ANOVA followed by post hoc Tuckey HSD tests; B. CAT activity between groups. Values are expressed as mean ${ }_{ \pm}$SEM from 9 rats per group. ${ }^{*} \mathrm{P}<0,05$ vs. P0 group by using one-way ANOVA followed by post hoc Tuckey HSD tests.

by maceration as follows: Mauli banana stem with one year age was taken approximately $10 \mathrm{~cm}$ from the hump. Then the stem was cleaned and cut up into small pieces and dried in a drying cabinet at $38^{\circ} \mathrm{C}$ for two days. Then the small pieces of Mauli banana stem were pounded and blenderized into a dry powder. The dry powder then was used for maceration. First, the dry powder put into an Erlenmeyer flask containing $500 \mathrm{ml}$ of $70 \%$ ethanol. Then the mixture was allowed stand at room temperature for five days. This process was performed up to three times. The resulting solution then filtered and concentrated in an evaporator at $40^{\circ} \mathrm{C}$. The dilution is then performed to obtain the ethanol extract of banana stem mauli $25 \%$. Dilution is done by mixing the extract with distilled water in the ratio of $25: 75$.

\section{Experimental animals}

The experimental animals used were 48 2-3 months old male rats (Rattus novergicus) weighing 200-250 gram. The animals were obtained from the Abadi Jaya farm at Yogyakarta, with the provision of being in healthy condition (active and well-formed). The rats were kept in housing cages with four animals per cage. Standardized food and water were performed under a light/dark cycle of $12 \mathrm{~h}$. The cages kept in a room that had a constant temperature of $25 \pm 1^{\circ} \mathrm{C}$. In order to prevent the animals from coming in contact with their feces and/or urine, a husk was added to the cages.

\section{Excision Wound}

The surgical procedures were performed under general anesthesia, by inhalation administration of diethyl ether. After anesthesia, the buccal mucosa was antiseptically cleaned with povidone iodine. Then a $10 \mathrm{~mm}$ length and $1 \mathrm{~mm}$ depth surgical mucosal wound was made in the buccal mucosa of all animals with a disposable scalpel.

\section{Treatment Protocol}

The animals were randomly divided into three groups. P0 was left to heal spontaneously, P1 was treated with Alocair (Aloe vera) topically and P2 was treated with $25 \%$ of Mauli banana stem. The treatment

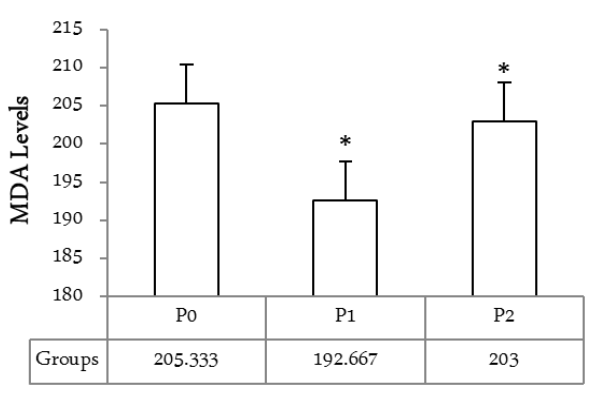

A

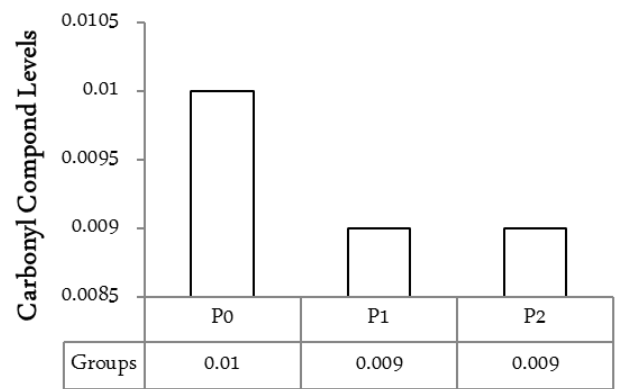

B

Figure 2. A. MDA levels between groups. Values are expressed as mean ${ }_{\mathrm{S}} \mathrm{SEM}$ from 9 rats per group. ${ }^{*} \mathrm{P}<0,05$ vs. P0 group by using Kruskal-Wallis followed by Mann-Whitney U tests; B. CC Levels between groups. Values are expressed as mean ${ }_{ \pm} \mathrm{SEM}$ from 9 rats per group. ${ }^{*} \mathrm{P}<0,05$ vs. P0 group by using one-way ANOVA followed by post hoc Tuckey HSD tests. 
applied to the wound site on the two times daily for three days. At the end of treatment, rats will be anesthetized using diethyl ether. Then the scars tissue were taken with $5 \mathrm{~mm}$ length, $3 \mathrm{~mm}$ wide, and $3 \mathrm{~mm}$ depth from the side of the wound. The sample tissues were immediately fixed in phosphate buffer solution $\mathrm{pH} 7$. Then the sample was ground to form a liquid. Subsequently the solution was taken and centrifuged at 3000 rpm for 45 minutes. The top layer of $500 \mathrm{~mL}$ were taken for further biochemical analysis.

\section{Biochemical Analysis}

Hydrogen peroxide measurement were made by FOX2 methods with slight modification [9]. SOD activity was measured by Misra and Fridovich method. MDA level of the homogenate was measured by the Buege and Aust method [10]. Carbonyl compound level in homogenate are estimated according by the DNPH method with slight modification [11].

\section{Statistical Analysis}

Statistical analysis was performed using SPSS for Windows version 16.0. Data were checked for normality (Shapiro-Wilk normality test) and homogeneity of variance (Levene's test). Then, data was divided into two assumptions. The normally and homogeneity distributed data were run with the parametric one-way analysis of variance (ANOVA) and followed by post hoc Tuckey HSD test. The non-normally and/or nonhomogeneity distributed data were run with the nonparametric Kruskal-Wallis Test and followed by MannWhitney $\mathrm{U}$ test. $\mathrm{P}$-values $<0.05$ were considered statistically significant.

\section{RESULTS AND DISCUSSION}

In this wound model, the SOD and catalase activity were determined. The results are presented in figure $1 \mathrm{~A}$ and $1 \mathrm{~B}$.

Figure $1 \mathrm{~A}$ and $1 \mathrm{~B}$ shows the SOD and CAT activities in wound model homogenate. Compared with the P0, the SOD activity of P1 and P2 increased significantly $(\mathrm{p}<0.05)$. In other hand, the CAT activity of the $\mathrm{P} 1$ groups is increased compared with P0 groups but not statistically significant. The CAT activity of P2 groups also increased if compared with P0 groups, but decreased if compared with $\mathrm{P} 1$ groups.

Wound healing is a natural process of regenerating dermal and epidermal tissue, and may be classified into three phases. The three phases of wound healing process are inflammation, proliferation and remodeling phase [12]. ROS and oxidative reactions play a signifi- cant role in those whole steps of wound healing, providing signaling and defense against microorganism [13]. Overproduction of these ROS results in oxidative stress is thereby causing cytotoxicity and delayed wound healing. Therefore, elimination of oxidant could be an important strategy in healing of acute and chronic wounds [14]. Hence, estimation of antioxidants like SOD and CAT in wound healing tissue is also relevant because this antioxidant hasten the process of wound healing by destroying these ROS.

Preventive antioxidants such as SOD and CAT are the first line of defense gainst ROS. SOD catalyzes radical superoxide dismutation producing hydrogen peroxide, whereas CAT remove it [15].

In our test, we found that in Mauli banana stem extracts groups, SOD activities increased significantly in wound tissue. Nonetheless, CAT activities had no change. These results show that Mauli banana stem extracts might have different effects on different antioxidant enzymes in wound tissue. Furthermore, the wound site also might absorb these extracts differently, and the metabolic enzymes in wound side were different as well. We hypothesize that the change of enzyme activities is related to the components or metabolites of Mauli banana stem extracts, which could affect enzymatic activities or enzyme contents. Further studies are needed to confirm this hypothesis.

To determined the impact of ROS production in the wound site, MDA and carbonyl compound were estimated. The estimated levels of MDA and carbonyl compound have been presented in figure $2 \mathrm{~A}$ and $2 \mathrm{~B}$.

Figure $2 \mathrm{~A}$ suggested that the lipid peroxidation level in the negative control group ( $\mathrm{P0}$ ) was higher as shown by high MDA content. However, treatment with standard as well as ethanolic extracts of Mauli banana stem significantly reduced the level of MDA in comparison to the negative control group. The results also suggested that standard treatment with alocair is more efficient than Mauli banana stem extracts.

Figure $2 \mathrm{~B}$ suggested that the carbonyl compound level in the negative control group (P0) was higher compared with the other two groups (P1 and P2). However, treatment with standard as well as ethanolic extracts of Mauli banana stem not significantly reduced the level of carbonyl compound in comparison to the negative control group.

The result of this study in MDA level suggests that the significant decreased might be correlated with alteration in antioxidant profile. The increasing activities of antioxidant enzymes will reduce the lipid peroxides (MDA) in treated rats both with alocair or Mauli ba- 
nanas stem extracts. On the other hand, this result study revealed that carbonyl compound levels had no change in the wound site. The reason maybe same with the reason as mentioned earlier in antioxidant activities parts in this discussion.

\section{CONCLUSIONS}

From this analysis, it can be concluded that the application of ethanolic extracts of Mauli banana stem extracts topically has different effects on oxidative stress status in buccal mucosa wounds healing process. The extracts significantly increased the SOD activity and decreased the MDA levels. On the other hand, the extracts were not significantly effect on CAT activity and CC levels. Further controlled clinical studies should observed and its modest efficacy.

\section{ACKNOWLEDGMENT}

Authors are thankful to Iskandar, dr. from Research Unit Mutiara Bunda Mother and Child Hospital, Martapura South Kalimantan Indonesian, for his support and encouragement during the process of writing this research.

\section{REFERENCES}

1. Suhartono E, Tanjung E, Muhammad Hafidz MS, Iskandar, Suhartono E (2014) Evaluation of antioxidant activity of some selected tropical fruits in South Kalimantan, Indonesia. J. Trop. Life. Science. 4(3): 210-215.

2. Miladiyah I, Prabowo BR (2012) Ethanolic extract of Anredera cordifolia (Ten.) Steenis leaves improved wound healing in guinea pigs. Univ. Med. 31(1): 4-11.

3. Logeeswari K, Sripathi SK (2012) Wound healing medicinal plants: a review. IJCEPR. 3(3): 199-218.

4. Koklu AHK, Akkol EK, Cankal DAU (2014) Biochemical and biomechanical assessment of effects of L-carnitine on oral mucosal wounds. Clin. Oral. Invest. DOI 10.1007/s00784-014-1329-8.
5. Apriasari ML, Iskandar, Suhartono E (2014) Bioactive compound and antioxidant activity of methanol extract Mauli Bananas (Musa sp.) Stem. IJBBB. 4(2): 110-115.

6. Sumathy V, Lachumy SJ, Zakaria Z, Sasidharan S (2011) In vitro bioactivity and phytochemical screening of Musa acuminata flower. Pharmacologyonline. 2: 118-127.

7. Imam MZ, Akter S (2011) Musa paradisiaca L. and Musa sapientum L.: a phytochemical and pharmacological review. 01(5): 14-20.

8. Kumar PR, Srivastava S, Singh KK, Mathad C, Thind PS (2014) Study of antioxidant and antimicrobial properties, phytochemical screening of sap extracted from banana (Musa acuminata) pseudostem. IJBR. 5(4): 649-658.

9. Suhartono, Triawanti, Yunanto A, Firdaus RT, Iskandar (2013) Chronic cadmium hepatooxidative in rats: treatment with haruan fish (Channa striata) extract. APCBEE Procedia. 5: 441-445.

10. Suhartono E, Triawanti, Leksono AS, and Djati MS (2014) Oxidative stress and Kidney glycation in rats exposed cadmium. IJCEA. 5(6): 497-501.

11. Suhartono E, Triawanti, Leksono AS, Djati MS (2014) The role of cadmium in proteins glycation by glucose: formation of methylglyoxal and hydrogen peroxide in vitro. JOMB. 3(1): 59-62.

12. Ilango K, Chitra V (2010) Wound healing and anti-oxidant activities of the fruit pulp of Limonia Acidissima Linn. (Rutaceae) in rats. Trop. J. Pharm. Res. 9(3): 223230.

13. Soneja A, Drews M, Malinski T (2005) Role of nitric oxide, nitroxidative and oxidative stress in wound healing. Pharmacol. Rep.57: 108-119.

14. Agarwal PK, Singh A, Gaurav K, Goel S, Khanna HD, Goel RK (2009) Evaluation of wound healing activity of extracts of plantain banana (Musa sapientum var paradisiaca) in rats. Indian. J. Expol. Biol. 47: 32-40.

15. Barua CC, Talukdar A, Begum SA, Buragohain B, Roy JD, Pathak DC, Sarma DK, Gupta AK, Bora RS (2012) Effect of Alternanthera brasiliana (L) Kuntze on healing of dermal burn wound. Indian. J. Expol. Biol. 50: 56-60. 